\title{
(息)
}

Citation:

Bonilla-Priego, MJ and Najera, JJ and Font, X (2011) Environmental management decision-making in certified hotels. Journal of Sustainable Tourism, 19 (3). 361 - 381. ISSN 0966-9582 DOI: https://doi.org/10.1080/09669582.2010.530350

Link to Leeds Beckett Repository record:

https://eprints.leedsbeckett.ac.uk/id/eprint/428/

Document Version:

Article (Accepted Version)

The aim of the Leeds Beckett Repository is to provide open access to our research, as required by funder policies and permitted by publishers and copyright law.

The Leeds Beckett repository holds a wide range of publications, each of which has been checked for copyright and the relevant embargo period has been applied by the Research Services team.

We operate on a standard take-down policy. If you are the author or publisher of an output and you would like it removed from the repository, please contact us and we will investigate on a case-by-case basis.

Each thesis in the repository has been cleared where necessary by the author for third party copyright. If you would like a thesis to be removed from the repository or believe there is an issue with copyright, please contact us on openaccess@leedsbeckett.ac.uk and we will investigate on a case-by-case basis. 
Bonilla-Priego, M.J., Nájera, J.J., Font, X

\section{ENVIRONMENTAL MANAGEMENT DECISION-MAKING IN CERTIFIED HOTELS}

Submitted for publication at the Journal of Sustainable Tourism

\section{ABSTRACT}

This article analyses environmental decision-making against two axes, motivations and decision-making processes, to understand the reasons for pro-environmental behaviour by the managements of Spanish EMAS certified hotels. Mixed methods were used to study perceptions of EMAS and reasons for being certified, with current and lapsed EMAS certified firms triangulated against expert interviews and documentary evidence. Four groups of hotels were differentiated: Strategic Hotels, (22\%) (with high levels of integrated environmental management), Followers, (48\%) Greenwashers (11\%) and Laggers (19\%) (with low levels of integrated environmental management). Most hotels were found to be internally driven in their purpose and ad hoc in their decision-making, with limited understanding of externally driven benefits and motivation for more systematic management systems. This questions the success of EMAS as both a continuous improvement management and as a market based regulation tool for hotels. Few hotels overall related high environmental standards to the possibilities of gaining market advantage: most wished to avoid legal challenges. The paper also illustrates the ways in which hotels opportunistically switch certification systems to get what they see as a better deal.

\section{Introduction}

Much research has been conducted to understand the environmental behaviour of firms in general and hotels in particular, as well as the influences determining their environmental behaviour. As firms become more aware of the importance of actions that can lead to greater sustainability, there is a slow process of organisational learning and change. Much of the early work in environmental management was ad hoc, driven either by short term ecosavings or public relations benefits. As the understanding of the importance and benefits of integrated environmental management has grown, so has the sophistication of actions, becoming more cooperative with stakeholders and becoming more demand led. This change in environmental behaviour is of particular interest because it could lead to potentially major changes throughout the hotel industry. Previous studies have provided a range of quantifications, categorisations and detailed explanations that are here used as the basis to develop a model to understand two aspects of organisational behaviour, the purpose of the actions and the decision-making process. Together these two elements form the basis of this 
paper to explain the ability of hotels to engage in environmental initiatives in a managed, structured way to allow performance improvements.

This study examines companies with a minimum environmental performance and management system: EMAS certified hotels in Spain. EMAS is an EU wide environmental management and auditing scheme that aims to improve the environmental management of organisations beyond legal compliance and provide independent reassurance (seehttp://ec.europa.eu/environment/emas/. There are a number of reasons behind this choice. First, EMAS assumes a minimum level of operational, planning, organisational, and communication practices. Second, EMAS requires public disclosure (as opposed to ISO14001 or any other certification in Europe), allowing a contents analysis of the self stated achievements (see Bonilla-Priego and Avilés-Palacios, 2008). Third, Spain has a sizeable population of certified hotels, being the second country (after Germany) in the number of registered EMAS (Eco-management and Audit Scheme) sites, and because hospitality is the leading industry using EMAS in Spain (140 out of 1122 registrations, as of March 2008). Finally, the number of certified firms using EMAS in Spain has remained stable, with few hotels entering and leaving the system. The characteristics of EMAS against other models have been widely reviewed elsewhere and for the sake of focus will not be reviewed again here (Golub, 1998; Kollman and Prakash, 2002; Morrow and Rondinelli, 2002; RowlandJones, Pryde and Cresser, 2005; Steger, 2000).

\section{Literature review}

\section{Purpose: from internally to externally driven}

We focus on better understanding two sets of reasons for environmental engagement widely reported in the literature, resource based internally driven reasons and legitimation, externally driven, reasons (Bansal and Roth, 2000a; El Dief and Font, 2010). 
Resource based actions tend to be internally driven and encompass cost savings on materials and processing, prevention of fines, and legislation driven interventions (Bansal and Roth, 2000b; Branco and Rodrigues, 2006; Dorfman, 1992; Kirkpatrick and Pouliot, 1996; Porter and van der Linde, 1995). Some literature suggests that in hospitality, cost reduction via operational efficiency is still the prime motive behind environmental measures (González and León, 2001; Tzschentke, Kirk and Lynch, 2004; Webster, 2000). This behaviour is characterised as internally driven due to a resource efficiency and productivity focus, including motivation of employees, the increase of legal certainty as well as the improvement of internal organization and documentation, the possibility to detect and minimize environmental and liability risks and reduce specific environmental impacts (Morrow and Rondinelli, 2002). What all of these motivations have in common is the aim of making the company internally robust: the external communication is opportunistic through an expectation of reputation and corporate image from resource efficiency actions.

A legitimisation approach seeks social approval, and encompasses actions to increase the environmentally friendly visibility of the firm, mainly to customers, distribution channels, and the media amongst other stakeholders. What makes this approach different is more the aim, rather than necessarily the type of actions- it is an externally driven, market led reasoning. The difference with the resource based model is the importance placed on environmental accountability by stakeholders, which has moved environmental communications from a voluntary and unregulated system to one where not only there is an expectation of actions, but of reporting in a way that ensures credibility and transparency.

Contrary to the examples used above, a different set of literature suggests that the main reason to implement corporate social responsibility programmes for firms in general (Clark, 1999) and international hotel chains in particular (Tsai et al., 2010) is the improvement of their image. Shareholders seem to welcome CSR messages. For example 
Nicolau found the publication of CSR press releases and media information to have the positive effect of increasing share price values on the following day (Nicolau, 2008). Government pressure has also encouraged the Spanish government owned chain of heritage hotels, Paradores, to certify all its hotels through EMAS, to become half of all the certified hotels in Spain - the remainder are a mixture of independent and chain hotels (BonillaPriego and Avilés-Palacios, 2008). Research results are, however, inconclusive, with reports both of how government legislation was the main reason for ISO14001 certification by hotel chains (Chan and Wong, 2006) and that non-governmental pressures have had more impact on firm's adoption of environmental strategies than government requirements (GonzálezBenito and González-Benito, 2006b).

Tourism certification has had little impact in differentiating firms according to their environmental credentials, arguably because these have targeted consumers directly but only with poor budgets and no marketing strategy (Ayuso, 2007; Font and Epler-Wood, 2007). Only in 2006, Chan and Wong (2006) found corporate governance and legislation as the only two discriminating factors found for ISO14001 certification. Since their study however, increasing tour operator interest in sustainable supply chain management has already driven some supplier actions, despite the operators not wanting to incorporate the myriad of ecolabels in their brochures (Ayuso, 2007). New tour operator-driven industry wide supplier standards are being implemented, and in due course could give accommodation providers marketing benefits (Schwartz, Tapper and Font, 2008). The systematic reporting of carbon driven environmental data is increasing fast due to increased pressures by investment funds for carbon reporting (Kolk, Levy and Pinkse, 2008). Using the Carbon Disclosure Project as an example, supplier carbon data will be increasingly required to account for indirect green house gas emissions, requiring tour operators to measure and then manage supplier performance (Thomas Cook Group, 2010). The argument put forward 
here is that besides government regulation, sustainability behaviour and reporting will increase due to green procurement clauses.

The literature suggests firms are moving from taking an internally to an externally driven approach to their management of environmental resources and impacts. Hotels with longer experience in environmental management saw environmental protection as a source of competitive advantage and not as an eco-efficiency tool (Carmona-Moreno, CéspedesLorente and De Burgos-Jimenez, 2004). There is evidence of environmental reactivity being related to regulation and media pressure, which later evolves into environmental proactivity driven by organisational stakeholders (consumers, supply chains, personnel, shareholders) (Bansal, 2005; Henriques and Sadorsky, 1999). This change will have both opportunities and threats for industry, legislators and lobby groups, as the increased stakeholder interest in sustainability creates new opportunities and the need for marketplace regulation. Clearly a firm can display both internally and externally driven behaviour as these are not mutually exclusive - hotels reduce their operational costs while also complying with buyer requirements. For this reason these will be treated as two variables and not two ends of a continuum.

\section{Decision-making: from ad hoc to planned}

Strategic environmental decision making can be referred to as the orientation a firm gives to its environmental questions and how it uses them as a competitive tool, as part of broader corporate decision-making, planning and management (Carmona-Moreno, Céspedes-Lorente and De Burgos-Jimenez, 2004). Several typologies to explain environmental organisational behaviour exist, depending on the factors that have been analysed as affecting the contents and implementation of these strategies (Álvarez Gil, Burgos Jimenez and Céspedes Lorente, 2001; Aragón-Correa et al., 2008; Klassen and Whybark, 1999; Schaefer and Harvey, 1998; Vastag, Kerekes and Rondinelli, 1996). Despite their differences, most studies agree in organising environmental strategies in consecutive stages from the most advanced 
(proactive) to the least committed (usually referred to as reactive or defensive), and mainly focusing on a combination of internal processes rather than (environmental) performance (Kolk and Mauser, 2002). The purpose of strategic management is to ensure that the organisation has devised a pathway to achieve its goals. Thus, following Roome's classification, compliance plus and proactive companies develop managerial systems to ensure that practices and decisions adopted to improve environmental performance work effectively (Roome, 1992). Therefore, the typology proposed in this paper focuses on the level of integration of environmental decisions with the rest of the corporate system, and explains behaviour as ranging from ad-hoc to planned.

Planned environmental behaviour requires the environmental strategy to be a synergetic part of the hotel's overall corporate strategy (Chung and Parker, 2008). These firms will have defined and allocated responsibilities, requiring top management (and often hotel chain) support (Bohdanowicz, 2005; Chan and Wong, 2006), formalised in appointing environmental champions and the creation of environmental departments (Del Brío, Fernández and Junquera, 2001). A department will be responsible and accountable for the design and implementation of an environmental management system (EMS), following similar procedures to the overall firms' quality management system of plan-do-check reportprocess (Sheldon and Yoxon, 2001). A correlation between financial performance and proactive corporate social responsibility management was reported for hotels both in the US (Lee and Park, 2009) and Spain (Claver-Cortés et al., 2007). These studies did not find environmental performance to be the cause of improved financial performance, but instead that more systematic quality management meant by extension more planned environmental management. It is arguably the strategic management of the firm that has a positive impact on both the financial and environmental performance. 
While the environmental (or now more typically sustainability or CSR) department needs to prepare its own plans and set targets, many of the strategies and actions need to be implemented integrated with other departments. Systems thinking proponents would argue that to be effective, once the company has adopted a proactive environmental attitude, changes to this strategy should be matched by changes to the control system (Brown, 1996; IHEI, 2005). These control systems supply information for decision making to ensure the attainment of environmental objectives and to provide evidence supporting the results of adopted actions (Henri and Journeault, 2010). They require knowledge systems to suit the purpose of communication, translation and mediation of sustainability information, with particular emphasis on accountability (Cash et al., 2003). A systems approach would require the measurement and monitoring of environmental performance to be linked to deployment and staff management, including employee performance evaluation (Schaltegger and Burrit, 2000). Embedded CSR programmes require systematic implementation and monitoring, with considerable implications for human resource management, as the example of Scandic Hotels shows (Bohdanowicz and Zientara, 2008).

The process of organisational learning to promote sustainable development seems to vary depending on management style. There is evidence that the decision to pursue environmental certification is strongly linked to having positive experiences of quality management systems (Worthington and Patton, 2005). For the larger firms in particular, environmental learning mechanisms seem to result from adapting a quality management system to a new problem, the environment. As such, larger companies that develop a proenvironment corporate culture put much emphasis on the development of controlling systems and reporting tools (Siebenhüner and Arnold, 2007).

The literature has often cited the importance of greening organisational culture to go beyond short term tactics to develop systematic organisational structures and practices 
(Harris and Crane, 2002). A strategic approach to environmental management requires an element of organisational redesign. Central to this is sustainability organisational learning, which requires changes in behaviour resulting from knowledge gained through reflection, or double loop learning (Siebenhüner and Arnold, 2007). This would be different from single loop learning, characterised by output changes at the operational level that do not affect the purpose or thinking of the firm. The process of organisational cultural change to embrace environmental issues as part of corporate behaviour is complex and multifaceted, yet we need to properly understand it to go beyond managing the environment through short term technical fixes- ultimately the institutionalisation of environmental thinking takes much longer than expected (Harris and Crane, 2002).

Academics have shown much interest in explaining business behaviour as a rational, purpose-driven and planned process; however, this is not always the case. The opposite of strategically planned behaviour has been defined as ad hoc. Ad hoc environmental behaviour is either not integrated in the hotel's strategy and control system (making environmental management a peripheral activity), or simply reflects the fact that the hotel does not have a clear strategy. There are sufficient opportunities in hospitality to implement environmental management actions with low investments and short payback periods, and sufficient technical advice opportunities (Bohdanowicz, 2007; IHEI, 2005) to suggest a hotel environmental behaviour does not become strategic because it has implemented some environmental initiatives.

Ad hoc behaviour can be both reactive to isolated external influences, for example public funding and technical assistance has driven hotels towards certification from Spain (Ayuso, 2007) to Singapore (Chan and Wong, 2006). Or it can be proactive, but not systematic, whereby companies make decisions on what to do without having assessed if that is the most effective action, or how it affects other aspects of the business. Having 
originally engaged with certification due to external funding being available, many certified firms state that their actions have not changed because of certification, but instead that it has provided management and control systems (Ayuso, 2007; Font, 2007). However not all firms see a management system as having a positive cost-benefit (MMA, 2006), particularly for small and medium firms (Hillary, 1999), conspicuous by their absence in EMAS (BonillaPriego and Avilés-Palacios, 2008).

The difference between ad hoc and planned behaviour could, therefore, be defined not only by the level of formality of the eco-control systems, but also by the organisational culture and learning processes. Research has shown the importance of managerial discretion to start CSR actions and the imperative of developing a business case to scale these up (O'Dwyer, 2003), and how, in organisational cultures with low management discretion, environmental personal values are constrained by organisational values (El Dief and Font, forthcoming). While small firms also justify their engagement based on economic reasons, personal ethical considerations prevail (Sampaio, 2009; Tzschentke, Kirk and Lynch, 2004; Tzschentke, Kirk and Lynch, 2008). Highly structured, top down systems from large firms will be planned and will provide management review opportunities at the end of the cycle- but their learning methods are slower and more bureaucratised. It can be argued that smaller firms will have more managerial discretion and shorter but less formal methods of evaluating success, and while their behaviour might be reactive to the funding and technical advice opportunities available, this does not necessarily make them any less strategic.

In summary, the literature provides evidence to argue that to understand the ability of the hospitality sector to embrace environmental change, we need to better appreciate the reasons for that change. This research will start by examining the "reasons why" behind investing in environmental management, followed by analysing the translation of the values into objectives and the level of operationalization by looking at the allocation of 
responsibilities, definition of objectives and espoused environmental values by staff. The argument continues by proposing that without the appropriate management systems, initial relatively easy actions will not lead to further change- yet we need to understand what is an appropriate management system according not to external definitions, but the firm's needs. A better understanding of these two sets of variables can then be put in the context of changes in stakeholder expectations on environmental performance from hotels, and the impact on hotels' behaviour.

\section{Methodology}

Mixed methods were used for this study. The main survey describes the purpose and decision-making processes of hotels and is described below. This main survey is supported by two other sources of data. First, by exploratory research conducted in 2006-7 to understand hotel management perceptions of the value of EMAS as a process. We gathered information about perceived use of data sources, indicators used to assess environmental objectives, the audience of the environmental report, and its use for hotel management. This survey provided some background explanations for the purpose and decision-making aspects that have been studied in this research (Bonilla-Priego and Aviles-Palacios, 2007). Second, causal research was used to exemplify issues arising from the main survey with hotels represented by the profiles developed in the quantitative data analysis. Ten hotels were interviewed, of which eight had abandoned EMAS, one was classified as Strategic and one as Lagger as per the labels explained in the results below. The headquarters of a chain with hotels in all three categories was also interviewed. Collectively the three stages of research provide a more complete picture of the reasons behind the behaviour of Spanish EMAS certified hotels. The reasons are fully explained in the discussion section.

\section{Main survey sample}

The population of this study is EMAS registered Spanish hotels, as listed in the European Commissions' website (http://ec.europa.eu/environment/emas/index en.htm) as of 
June 2008. The survey population consisted of 139 hotel sites certified, belonging to 44 organisations, many of them owning only one hotel. The Spanish owned Paradores chain owns over $50 \%$ of the population (74 of the 139 establishments). The first mailing took place in November 2008 and a follow up a month later, after confirming environmental managers or engineers for each hotel by telephone, or in their absence the person responsible for this topic. In this phone call we established the management structure of the firm, particularly important for chains with more than one certified establishment. In the case of Paradores, environmental issues are centrally managed, while all other chains were decentralized at the time. This reduced the sampling frame to 66 management units, as Paradores offered only one answer.

34 valid responses were received out of 66 possible answers. Data inconsistencies and anomalies in seven questionnaires reduced the sample to 27 (40.9\% response rate). The final sample is 27 management units representing 100 establishments out of the 139 EMAS certified hotels. Over $70 \%$ of establishments represented in the survey have 4 stars and cater for a predominantly summer sun market. They are medium sized hotels, with less than 300 bedrooms in most cases. The response rate is arguably good but the number of establishments might be thought insufficient, which limits the potential to extrapolate results. Data analysis methods were designed assuming a scarce dataset, as will be seen below.

\section{Survey design}

The survey was designed assuming a small sample to understand the environmental manager's judgement on company behaviour (importance of environmental objectives driven by internal or external stakeholders), and the planning and operationalisation of environmental management. The limited number of articles dealing specifically with this topic for hotels (Álvarez Gil, Burgos Jimenez and Céspedes Lorente, 2001) informed part of the survey, together with cross-sectoral studies and recommendations from the EMAS 
regulations as this system promotes a move for a company to initiate a process to integrate environmental objectives in daily operations as well as strategic issues (Clausen, Keil and Jungwirth, 2002). Additionally, independent variables to identify hotels and their motivations to become certified and to choose EMAS were included. A pre-test with EMAS certification consultants working with hotels took place to validate the questions: their wide experience allowed them to discuss and compare a range of motivations and operational practices. We widened the list of environmental motivations (for example including the importance of subsidies) and asked if environmental actions were prioritised first by environmental objectives or budget.

We created a variable to analyse the importance of internally driven reasonsmeeting legal requirements, cost savings and the opportunity to reduce environmental impacts and risks (González-Benito and González-Benito, 2005; Morrow and Rondinelli, 2002) (see table 1). External objectives items (see table 2) represent both the motivations (client pressures, competitive advantage) as well as communication practices both to clients and suppliers (Aragón-Correa et al., 2008; González-Benito and González-Benito, 2006a) and the influence of external stakeholders in defining environmental objectives.

Insert Table 1 here

Insert Table 2 here

Environmental planning and organisational practices (decision-making axis) were represented by two types of items. First, a series of questions regarding the person responsible for environmental management- role in the organisation, planning process and definition of objectives (Vastag, Kerekes and Rondinelli, 1996), from which a variable was created (see table 3). This variable along with questions regarding the qualifications and training in environmental management and the opportunities for staff involvement (see 
table 4) were included as proven significant in previous studies (Álvarez Gil, Burgos Jimenez and Céspedes Lorente, 2001; Aragón-Correa et al., 2008).

Insert Table 3 here

Insert Table 4 here

The final section considered if the control systems in place help or hinder the manager in improving the environmental performance of their hotel, as the control system is supposed to encourage organizational change (Roome, 1992). Along with this, we surveyed the indicators used to evaluate the organization environmental performance and the environmental manager performance (Brown, 1994).

The survey questions used are shown in the tables within this paper.

\section{Data analysis}

To obtain the constructs related to internal orientation, external orientation and strategic and organisational management, exploratory factor analysis was undertaken following principal components analysis. In this process several items were eliminated due to poor correlation, and a single factor for each case was obtained (see tables 5, 6 and 7). To test the construct consistency the Cronbach's alpha was used, obtaining acceptable values in all instances (see table 8).

Insert table 5 here.

Insert table 6 here.

Insert table 7 here.

Insert table 8 here.

From the factors obtained, a hierarchical cluster analysis was conducted with the objective of classifying the survey elements. Ward's method (1963) was followed, using squared Euclidean distance as a similarity measure, a widely used technique in the social sciences. From the outcomes of this first analysis and following the advice from Aldenderfer and Blashfield (1984) and Hair et al. (1999) regarding choices of optimal numbers of clusters 
based on cluster coefficients, it was determined that four groups were best suited. From this data the analysis was undertaken with this number of groups in mind following a non hierarchical process based on the K-means algorithm, obtaining the same results. Following Cea D'Ancona (2002) this process can, to a certain extent, help to validate the correction of the classification undertaken. In our case, the results obtained were identical in both cases, suggesting the validity of the analysis undertaken.

\section{Results}

The survey resulted in four distinctive groups of hotels according to their reasons for, and methods of engaging in, environmental management, ranked from the least committed to the ones with an environmental behaviour most strategically oriented [see table 9]. Two salient issues are worth mentioning at this early stage. First, despite the apparent engagement through being EMAS certified and the requirements this supposes, there was a varied range of practices. Second, that hotels belonging to the same chain were found as adopting widely different practices, as reported elsewhere (Céspedes and De Burgos, 2004).

The fact that hotels considered in this research are certified under EMAS is relevant when making groups and makes a difference with respect to other typologies found in the literature, as all hotels considered have an environmental policy, prepare an environmental report, and some others factors that are usually considered when classifying companies from reactive to proactive. However, being certified does not mean they have a proactive strategy: the issue here is not just having an environmental management system components, but how these are used. This led us to research the reasons why hotels chose this certification, how they define their objectives, and to what extent they integrate their environmental management system in the general management system, all of which was part of differentiating the four groups of hotels.

Insert table 9 here 
The Strategic Group. This group scores the highest in all three variables considered. When defining environmental objectives they are focusing on the most important environmental aspects as well as legislation. These hotels not only listen to their engineers, but also to the market signals, as they also pay high attention to external stakeholders and look at competitors when setting targets, taking a holistic approach environmental management (Álvarez Gil, Burgos Jimenez and Céspedes Lorente, 2001; Vastag, Kerekes and Rondinelli, 1996). The third variable (level of planning and organizational practices) shows that environmental issues are highly integrated in these hotels communications and organizational practices. External communications scored the highest in the use of environmental issues in marketing campaigns and in relation to suppliers, while also communicating with employees including environmental training.

The Followers. They score positive on all three variables, but at a considerably lower level than the strategic group. These hotels analyse their specific environmental aspects as well as external conditions that affect the company, and tackle all three aspects of internal and externally driven objectives and communicational and organizational practices. However, they consistently perform at a lower level than the Strategic hotels. Both Strategic and Followers declared to have chosen EMAS over other certification systems because of EMAS' specific characteristics (arguably being stricter and allowing the showing of higher commitment and performance).

Greenwashers. This is the least numerous group, labelled Greenwashers because they score positively only on external objectives. They basically declare to look at the market, competitors and stakeholders when defining plans and setting targets, while admitting to ignoring significant environmental aspects and maintaining very poor organizational practices (despite EMAS' requirements to do so). This behaviour, together with the fact that the main reason to choose this certification system was the promotional 
(and subsidised) campaign launched by government [see table 10], could make us think they have an opportunistic behaviour. In this case is difficult to understand why they keep being certified in this system, as EMAS is not specially well-known (Bohdanowicz, 2005) and is supposed to be one of the most demanding schemes (Morrow and Rondinelli, 2002).

Insert table 10 around here

The Laggers. This group is made up of hotels that despite all having been certified for more than six years, they consistently achieve low scores in all three variables. The information provided about how the environmental management system is run shows poor planning and organizational practices not integrated into the general management system. Our research shows that one of these has abandoned EMAS since the survey while keeping certified under ISO 14001, and when interviewed they stated the reason being that it is considered less expensive due to not having to prepare an environmental declaration. This group's score on external objectives is the lowest, reporting negligible market demand.

The behaviour of these Laggers can be explained in a variety of ways. First, EMAS certification had been promoted as a tool to ensure checks against legislation compliance, one of the few drivers seen for small firms in the literature (Worthington and Patton, 2005). Second, the early rounds of certification were subsidised. Third, in many cases the subsidy has been used to finance external consultants effectively outsourcing the tasks (but also the knowledge) of environmental management and reporting. This lack of internalisation has reduced the learning opportunities.

Although all hotels (except the Laggers) claim to listen to and learn from stakeholders when defining objectives, it is not clear how. It is not clear either how the environmental declaration is used as a communication tool. It is worth considering that while environmental disclosure is compulsory under EMAS, the type and amount of 
information varies among hotels and therefore the decisions users can base on this information. The preliminary 2006-07 survey told us that academic researchers were the largest proportion of users, as reported by nearly 30 hotels that keep records of requests for the reports, and in very few cases was the environmental declaration on the hotel's web page. Hoteliers declared that the primary purpose of the environmental declaration is to achieve certification, compared to stakeholder disclosure or internal management, while the main reason to read competitors' environmental declaration is to select the own set of indicators to include in their report. Comparing environmental declarations is complex, as hotels neither disclosure the same indicators nor use the same metrics (Bonilla-Priego and Avilés-Palacios, 2008).

As explained in the methodology section, the last part of the questionnaire explored performance evaluation and incentives practices. Therefore, after presenting results referring to planning and organisational practices, it is interesting to look at the results relating to the last stage of the strategic plan-do-check process: monitoring strategy implementation (see table 11). Results concerning the use of performance measures, budgeting and incentives let us know how the information recorded by the environmental performance system is used to evaluate the environmental strategy. Every hotel claimed to consider success to be shown by the implementation of the measures, but were unclear when asked how they evaluated success. Some declared to neither use indicators to evaluate the organization, nor the environmental manager/responsible, and evaluation by managing budgets was considered in less than half of the cases, and being much more important for chain hotels. Evaluation of the environmental manager is negligible- most declared not to have any indicator to evaluate this person's performance. In those cases where this evaluation was undertaken, the only evaluation indicator was whether the environmental practices were undertaken (and not how successful they had been in addressing the impacts) and in few cases staying within budget. Results were significantly 
better for the Strategic group, who have relatively more defined environmental management systems.

Insert table 11 here

\section{Discussion}

Results will be discussed in the context of the two axes that have informed this research: the purpose behind their management of environmental impacts and the level of integration of environmental decisions into the corporate strategy. It is important to remember that we are researching companies already achieving a complex and demanding certification standard, and that other older studies would classify all these companies as being environmentally proactive- see for example, Roome (1992) and Henriques and Sadorsky (1999). This study looks at this arguably higher level group in greater detail than before.

The analysis of the purpose for engagement shows a relationship between the range of variables considered when setting environmental objectives and the main motivations to adopt an environmental management system, and to choose EMAS as the main certification system. The results display different strategies adopted by hotels despite choosing the same certification system. These differences could be the result of several phases of implementation, as this research has been undertaken at a specific moment in time and is not able to discern whether hotels are moving from a defensive to an offensive phase, as explained by VROM (1997).

Environmental legal compliance has been referred to on many occasions as one of the main motivations to adopt and certify an environmental management system (Morrow and Rondinelli, 2002) and also as one of the main benefits. This is especially applicable to Spain's complex environmental regulation, with laws being issued by local, regional and national authorities. And this has been the main reason addressed by Laggers for certification, together with the will to show environmental commitment. For these hotels, EMAS could 
fulfil their expectations as it helps to get their house in order and to display an ecolabel which demonstrates due diligence in case of an environmental crisis, reducing liability risks. For example, during interview one of the hotels in this group explained that they opted for certification after non-legal compliance of their boilers and heating system. However, simply adopting a compliance strategy will lead to a short term operational focus on environmental problems, without further ambitions to go beyond the current legislation. The lack of commitment is obvious and it is not surprising that one of the hotels in this group has already abandoned EMAS since the primary research was conducted. Therefore, when undertaking the process of getting certification, some hotels decided to keep their environmental strategy to a minimum, paying minimal attention to both internally and externally driven reasons to adopt environmental initiatives. This is the strategy adopted by the Laggers, who score the lowest in our model. There is no intent to use certification to gain a competitive advantage. It would be interesting to research their attitude in relation to other competitive variables, to see if there is a lack of knowledge about where the market is moving to or just perceiving their environmental attitude as acceptable and not possible to take any competitive advantage.

insert figure 1 here

Most hotels are positioned at the other end of figure 1 . The most relevant question in relation to the Strategic group is the attention paid to externally driven forces, that is, on a demand led approach. Followers and Strategic businesses do not differ significantly on the way they look at their environmental aspects to set targets, but on the effect that externally driven forces have on their environmental strategy and on the external communication of certification. Few hotels go beyond the EMAS requirements for stakeholder communication through the preparation of the environmental statement and the creation of mechanisms for third parties to contact the certified company. Despite this requirement, results show 
that a standard cannot force companies to consider the market in their strategic analysis.

Few hotels considered gaining market advantage while reducing impacts as the main reason for certification. Thus, the strategy adopted by the Followers represents a sub-optimal solution, focusing on internal aspects at the same level as the Strategic group, while being unaware of the advantages of active external communication and missing an opportunity to gain a competitive advantage through superior ecological performance (Worthington and Patton, 2005). In summary, most hotels do not have a clear perception of environmental management as a resource that provides a competitive advantage, despite their engagement in certification.

The transition claimed in the literature from resource based to demand led change is proving more complex than expected by those hotels aiming to gain competitive advantage. This expectation is the main difference between the Followers and the Strategics, with the latter expecting, but struggling, to find a successful green marketing strategy. Expectations that the label would lead to consumer interest fail to consider the basics of green consumer marketing (Font and Epler-Wood, 2007). For example, both the chain Sol Meliá and hotels in the theme park Port Aventura reported during interviews that while environmental management is now part of the firm (within environmental engineering), there is no understanding by the marketing team of how to use this as a market-led competitive advantage tool, with very coarse expectations that displaying a logo will increase sales.

Hotel groups are reformulating their strategies. Some large Spanish hotel chains are taking a group approach to environmental management, with the dual purpose of reducing operational costs and providing evidence of good governance to an increasing number of corporate buyers and tour operators. While individual hotels within these chains had received environmental certificates, there was no group strategy and each hotel's general manager took independent decisions out of personal conviction. Sol Meliá for example, after 
having six EMAS certified hotels in 2005, is abandoning the system by the time this research was conducted, explaining during our interview this approach and is now moving towards a group management and certification approach after corporate buyers have requested independent evidence of environmental performance. They are moving to the external certification Biosphere Hotels and supply chain management certification Travelife. Their group approach to sustainability management is supported by detailed financial and carbondriven environmental indicators, the first for internal (eco-savings) and the second for external (green procurement) management reasons. Some hotels have abandoned EMAS but stayed with ISO 14001, considered by some hoteliers as less demanding, while others have moved towards market-led systems. And this is also why, when hotels were surveyed by the Balearic Islands' regional government on how to improve the certification system, hotels demanded advertising campaigns to promote and spread information about EMAS (Govern de les Illes Balears, 2006). As a response, some governments are instead aiming to incorporate EMAS as a public procurement requirement.

The eight hotels interviewed that did not renew their certification claim that they have used the initial advice received to achieve the environmental improvements with the best return on investment, while they perceive continued improvements to be too costly for the low market demand for certified companies. As incentives will be phased out, our data suggests that the Followers, Laggers and Greenwashers will either not renew their certifications, engage with the philosophy behind certification, survive in the system by adopting the minimum requirements, or change to be certified by any scheme that is perceived as more efficient either because it is considered less costly by hoteliers or better recognised or paid by the market. Finally, the claimed lack of recognition of the market will lead us to wonder about the misled marketing strategy of the green washers. 
In summary, there is no direct relationship between the motivations to be certified and the chosen certification system. Different reasons, traditionally referred to in the literature, drove hotels to EMAS as their choice. Furthermore, the prime reason why hotels chose this system shaped the strategic analysis behind setting objectives to improve their environmental performance. Few hotels expected to gain a competitive advantage from EMAS certification and to work hard in this direction. In these cases, the transition from taking an internally to an externally driven approach to manage environmental resources is slow. These companies expect market signs of interest, currently in the form of tour operators' requirements.

The second axis of this research, the level of management integration, would suggest that all hotels accomplishing EMAS requisites should have a strategic planned behaviour. However, all the elements required by EMAS (environmental policy, objectives and targets, allocation of responsibilities...) have to permeate throughout the business. Results will be discussed in relation to the level of integration of environmental decisions in the context of environmental organisational learning.

The four clusters show different levels of integration between the environmental strategy and control system that should supply information for decision making (Brown, 1996; IHEI, 2005). The two clusters that show little integration of EMS into overall management structures correspond to hotels that are paying little attention to the process of setting environmental objectives, and giving limited importance to environmental risks and market pressures. The results show mostly that environmental management is not strategically internalised, as found in previous research of ten EMAS certified companies in Spain where only two showed integration of environmental issues in strategic planning and use of environmental accounting practices (Albelda-Pérez, Correa-Ruiz and Carrasco-Fenech, 2007). Obviously, the Laggers do not need a strategic planned behaviour as their 
environmental actions are closely related to legal compliance and other environmental management opportunities with short paybacks periods. In fact, some of the Laggers have been certified for ten years.

The Strategic and Follower hotels demonstrate better than average communication, planning and organisational practices, but they display poor performance in monitoring, appraisal and rewarding processes. Although all these hotels record information on their environmental performance, as it is disclosed in their environmental statement and used for internal planning, it is not used to evaluate the environmental manager's performance to align managers' efforts with company environmental objectives. Only in one case belonging to the Strategic cluster, was the environmental manager's bonus linked to achieving environmental objectives- a practice otherwise common for senior management positions. Roome (1992) found that one of the main limitations to the success of an environmental strategy was an effective internalization of environmental principles. This would mean treating the environment as a core activity, with robust external social accounting information and a valued environmental management control system. The results show that in only in half of the cases where environmental indicators were used to evaluate the organization, were they also used to evaluate the environmental manager. Measuring environmental performance implies that the environmental manager shares the environmental risks and is aware of the state of the art on behalf of the company about their most important environmental aspects, targets and performance. The actions reported show that the environmental function does not receive the same treatment as other functions in the companies. Basically, environmental management objectives are not considered as real targets, are likely to not be sufficiently ambitious in the first place and not considered under the control of the environmental manager. 
We found that environmental proactive (i.e. Strategic) companies will invest in environmental information systems to align management decisions with the environmental strategy. This confirms the literature suggesting that companies that use performance indicators to ensure higher levels of control are also more proactive (Henri and Hourneault, 2008; Brown, 1996). This parallelism is shown in figure 2, where the size of the bubbles shows the level of the integration. The integration of the control system does not depend on the size of the company. We found companies of different sizes in all four clusters, proving environmental organisational learning can take many forms. Small companies usually complain about limited time and financial resources as a constraint for outsourcing advice. However regional governments in Spain are pump priming companies to start engaging with financial and expert help. But interviews revealed that the challenge is in maintaining the environmental management systems- the main reason stated for companies having left EMAS. Deeper conversations highlighted that the lack of integration of environmental management into other managerial functions caused this economic inefficiency. Complaints related to the requirement of preparing an environmental statement with an environmental policy, environmental plans, objectives, targets and the level of achievement for the three years period- often these companies said they just wanted to "get on with it". All this information should be provided by the management system as planned and systematically used by each function.

In summary, the level of integration of environmental decisions in the management control system is lower than expected considering these businesses are certified under EMAS. This gap is due to the fact that the environmental strategies adopted are not homogeneous. In the cases where the level of integration is lower than the required for the strategic intent, it is difficult for hotels to remain in the system. 


\section{Conclusions}

EMAS certification is aimed at showcasing best environmental management practice- there are clear requirements for management procedures to be in place including public reporting, which coupled with a continuous improvement system presupposes certified firms should have both high performance but also showcase themselves as highly committed and organised firms. More worryingly, the results from this study show the incentives used for hotels to be certified to not be successful in embedding the ethos of environmental management, both in its purposes and in its management methods. EMAS provides a frame for companies to apply organizational as well as technical innovations needed to improve environmental performance. The evidence from this article has, however, shown that many of the firms have not engaged in reflective or double loop learning that should embed sustainability in their organisational practices.

The implications of this study are that a significant change in the reasons and strategic intent for hotels to engage in sustainability innovations will have consequences on how these hotels engage, on the type of environmental actions taken, the systems used to take decisions and particularly how actions are monitored and reported. A review of industry trends has shown a shift from internal, resource based reasons for environmental engagement to external legitimisation reasons, encouraged by a number of stakeholder pressures depending on the type of hotel. Those firms that have both the organisational culture that embraces sustainability, and the organisational systems to manage the processes, will be best placed to tackle these new opportunities. Most certified hotels do not perceive environmental management to be a source of competitive advantage. Those that do are reconsidering which certification programme offers them best recognition by external stakeholders.

Further research is needed, however, on the policy instruments that can be used to successfully engage hospitality firms to not only display some of the changes in short term 
behaviour while an external incentive is available, but to encourage change at a deeper, more permanent and self nurturing level. The small number of environmentally certified hotels per country requires further quantitative research that aims to achieve generisable results, and takes a multiple country sample- with the resultant challenges to interpret how supposedly comparable policy instruments are used differently in different countries. 
Table 1. Items used to measure the environmental internal orientation*

Environmental objectives are defined in my company taking into account: legal compliance

Environmental objectives are defined in my company taking into account: significant

environmental aspects

The main motivation to implement an environmental management system was cost savings

* All the included items in this dimension was measured using a ten-point Likert scale (level of agreement to these sentences) 
Table 2. Items used to measure the environmental external orientation*

The main motivation to implement an environmental management system was responding to market/customer pressure

The main motivation to implement an environmental management system was to gain competitive market advantage

We regularly sponsor events and/or collaborate with organisations engaged in environmental conservation

We use our environmental policy and actions as a commercial strategy (environmental quality labels and certification)

Our suppliers have access to our company's environmental policy

Environmental objectives are set taking into account the opinion of stakeholders (clients, suppliers, investors...)

* All the included items in this dimension was measured using a ten-point Likert scale (level of agreement to these sentences) 
Table 3. Creation of the variable "environmental management process"

\begin{tabular}{|l|l|}
\hline Variable & Score \\
\hline environmental management? & +1 if positive, +0 if negative \\
\hline Is there a person responsible for & \\
\hline the environmental manager and the hotel & points, min 0 points) \\
\hline general manager? & \\
\hline Is the environmental manager part of the & +1 if positive, +0 if negative \\
\hline motel's management team? & \\
\hline Is there an environmental committee in the & +1 if positive, +0 if negative \\
\hline hotel? & environmental manager alone \\
\hline Who decides the environmental management & +1 if undertaken by the environmental \\
\hline objectives? & management committee or the hotel \\
\hline
\end{tabular}


Table 4. Items to measure the strategy and organisational management variable*

Environmental management process (see table 3)

Environmental staff training is a priority of your company

All employees know the environmental objectives of this company

All employees know and have access to our environmental policy

There are channels for employees to make suggestions for the environmental management

of the company

We have a control system that allows us to have all the information needed to define environmental objectives

We are capable of estimating the costs and investments undertaken for environmental management in this company

* All the included items in this dimension was measured using a ten-point Likert scale (level of agreement to these sentences) 
Table 5. Factor loadings for the internal orientation construct

\begin{tabular}{|l|l|}
\hline Item & Factor loading \\
\hline Significant environmental aspects & \\
\hline Environmental objectives are defined in my company taking into account: & 0.943 \\
\hline legal compliance & \\
\hline The main motivation to implement an environmental management system & Dropped \\
was cost savings & \\
\hline
\end{tabular}


Table 6. Factor loadings for the external orientation construct

\begin{tabular}{|l|l|}
\hline Item & Factor loading \\
\hline was responding to market/customer pressure & 0.705 \\
\hline The main motivation to implement an environmental management system competitive market advantage & 0.770 \\
\hline We regularly sponsor events and/or collaborate with organisations & Dropped \\
engaged in environmental conservation & \\
\hline We use our environmental policy and actions as a commercial strategy & 0.755 \\
\hline (environmental quality labels and certification) & \\
\hline Our suppliers have access to our company's environmental policy & 0.718 \\
\hline Environmental objectives are set taking into account the opinion of \\
stakeholders (clients, suppliers, investors...)
\end{tabular}


Table 7. Factor loadings for the Strategy and organisational management construct

\begin{tabular}{|l|l|}
\hline Item & Factor loading \\
\hline Environmental management process (see table 3) & 0.727 \\
\hline Environmental staff training is a priority of your company & 0.798 \\
\hline All employees know the environmental objectives of this company & 0.727 \\
\hline All employees know and have access to our environmental policy & Dropped \\
\hline There are channels for employees to make suggestions for the & 0.795 \\
\hline $\begin{array}{l}\text { We hironmental management of the company } \\
\text { needed to define environmental objectives }\end{array}$ & \\
\hline $\begin{array}{l}\text { We are capable of estimating the costs and investments undertaken for } \\
\text { environmental management in this company }\end{array}$ & Dropped \\
\hline
\end{tabular}


Table 8. Factor analysis results summary

\begin{tabular}{|l|l|l|l|}
\hline Factor & Variation explained & Items & Cronbach's alpha \\
\hline Internal orientation & $88.99 \%$ & 2 & 0.876 \\
\hline External orientation & $56.30 \%$ & 5 & 0.781 \\
\hline Strategic and organisational & $58.19 \%$ & 4 & 0.760 \\
\hline management & & & \\
\hline
\end{tabular}


Table 9. Analysis results: Final Cluster Centres

\begin{tabular}{|c|c|c|c|c|}
\hline & \multicolumn{4}{|l|}{ Clusters } \\
\hline & Strategic & Followers & $\begin{array}{l}\text { Green } \\
\text { washers }\end{array}$ & Laggers \\
\hline $\begin{array}{l}\text { Importance of internal } \\
\text { objectives }\end{array}$ & 0.75548 & 0.57731 & -0.92263 & -0.79241 \\
\hline $\begin{array}{l}\text { Importance of external } \\
\text { objectives }\end{array}$ & 1.12269 & 0.16263 & 0.88614 & -1.10477 \\
\hline $\begin{array}{l}\text { Level of planning and } \\
\text { organizational practices }\end{array}$ & 1.09281 & 0.20925 & 0.02221 & -0.70180 \\
\hline Number of hotels & 6 & 13 & 3 & 5 \\
\hline
\end{tabular}


Table 10. Reasons for choosing EMAS

\begin{tabular}{|l|l|l|}
\hline & Subsidies from & Because of EMAS' own \\
characteristics
\end{tabular}


Table 11. Environmental monitoring and evaluation indicators

\begin{tabular}{|l|l|l|l|l|}
\hline & \multicolumn{2}{l|}{$\begin{array}{l}\text { Implementation of planned } \\
\text { environmental practices as } \\
\text { evaluation indicator }\end{array}$} & $\begin{array}{l}\text { Budgetary compliance as } \\
\text { evaluation indicator }\end{array}$ & \multicolumn{2}{l|}{} \\
\hline & No & Yes & No & Yes \\
\hline Strategic & 1 & 5 & 2 & 4 \\
\hline Followers & 0 & 13 & 7 & 6 \\
\hline Greenwashers & 0 & 3 & 2 & 1 \\
\hline Laggers & 0 & 5 & 5 & 0 \\
\hline
\end{tabular}


Figure 1. Internal vs external motivations

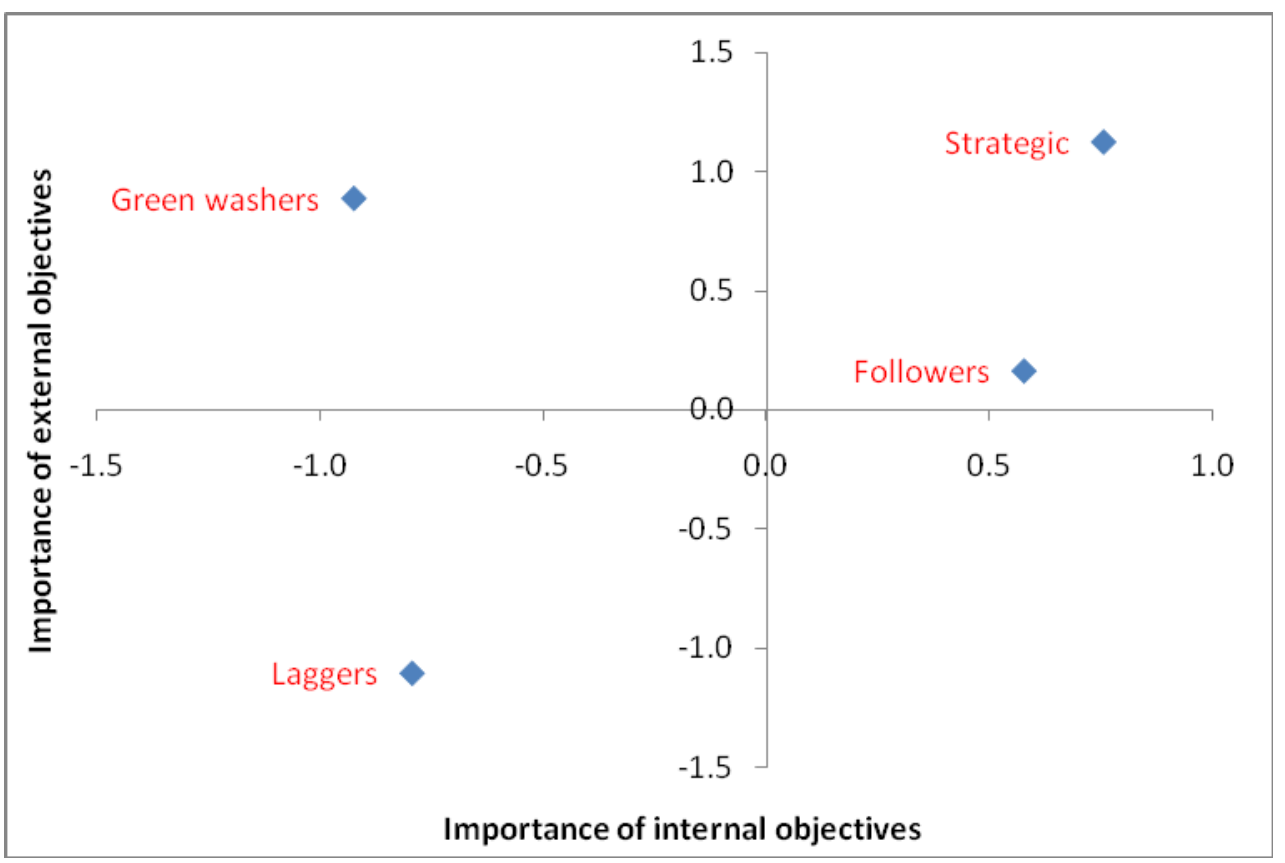


Figure 2. Planning and organizational practices

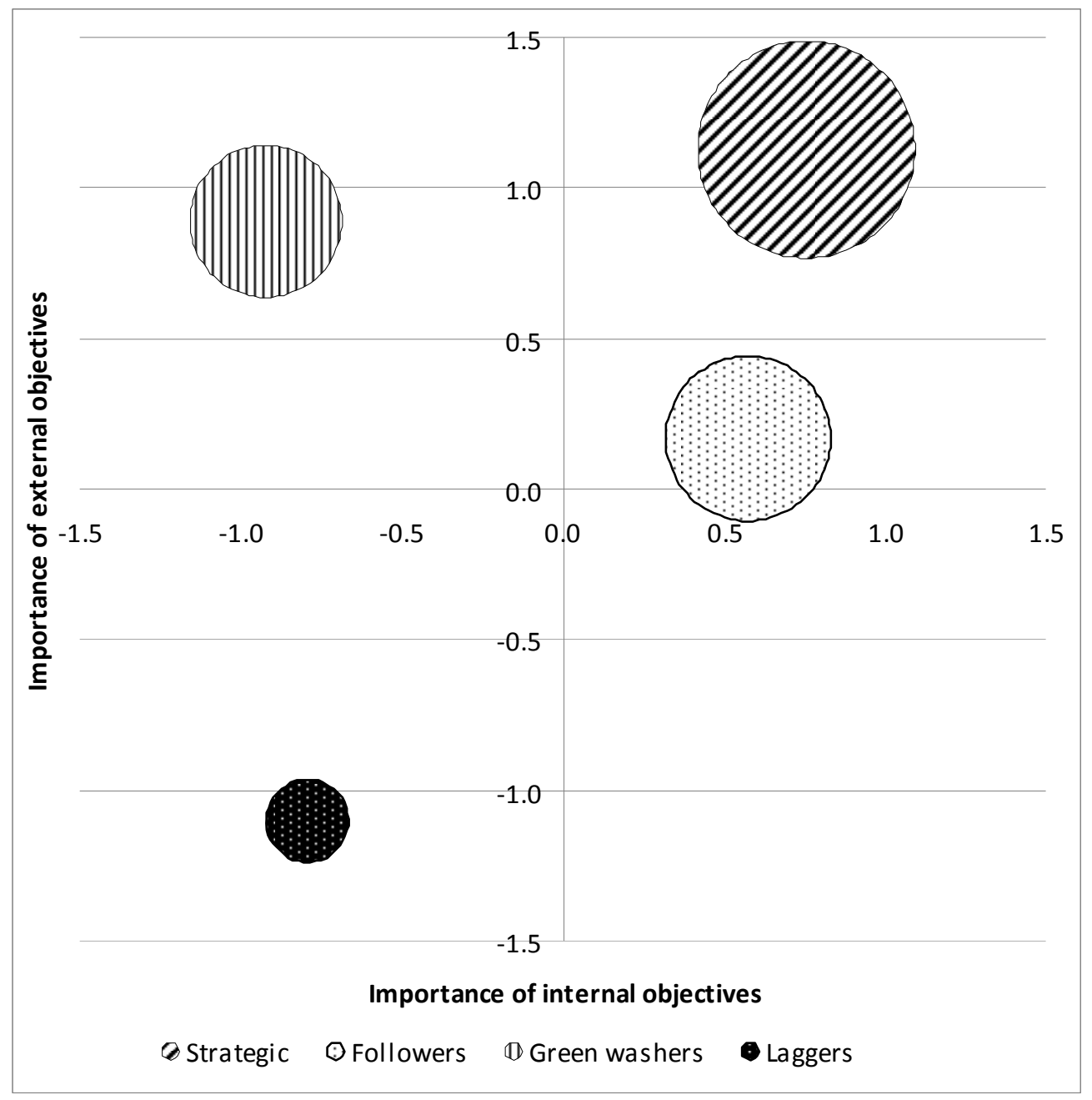


Albelda-Pérez, E., Correa-Ruiz, C. and Carrasco-Fenech, F. (2007) Environmental management systems as an embedding mechanism: a research note. Journal: Accounting, Auditing \& Accountability Journal 20 (3), 403-422.

Aldenderfer, M. S. and Blashfield, R. K. (1984) Cluster analysis. Newbury Park: SAGE.

Álvarez Gil, M. J., Burgos Jimenez, J. and Céspedes Lorente, J. J. (2001) An analysis of environmental management, organizational context and performance of Spanish hotels. Omega 29 (6), 457-471.

Aragón-Correa, J. A., Hurtado-Torres, N., Sharma, S. and García-Morales, V. J. (2008) Environmental strategy and performance in small firms: A resourcebased perspective. Journal of Environmental Management 8688-103.

Ayuso, S. (2007) Comparing Voluntary Policy Instruments for Sustainable Tourism: The Experience of the Spanish Hotel Sector. Journal of Sustainable Tourism 15144-159.

Bansal, P. (2005) Evolving sustainably: A longitudinal study of corporate sustainable development. Strategic Management Journal 26 (3), 197-218.

Bansal, P. and Roth, K. (2000a) Why Companies Go Green: A Model of Ecological Responsiveness. Academy of Management Journal 43 (4), 717-737.

Bansal, P. and Roth, K. (2000b) Why companies go green: a model of ecological responsiveness. Academy of Management Journal 43 (4), 717-736.

Bohdanowicz, P. (2005) European Hoteliers' Environmental Attitudes: Greening the Business. Cornell Hotel and Restaurant Administration Quarterly 46 (2), 188204.

Bohdanowicz, P. (2007) Theory and Practice of Environmental Management and Monitoring in Hotel Chains. In S. Gossling, C. M. Hall, \& D. B. Weaver (Eds.), Expert meeting on sustainable tourism; Sustainable tourism futures : perspectives on systems, restructuring and innovations (pp. 102-130). Helsingborg, Sweden: New York.

Bohdanowicz, P. and Zientara, P. (2008) Corporate social responsibility in hospitality: Issues and implications. A Case Study of Scandic. Scandinavian Journal of Hospitality and Tourism 8 (4), 271-293.

Bonilla-Priego, M. J. and Avilés-Palacios, C. (2008) Analysis of Environmental Statements Issued by Spanish EMAS-Certified Hotels. Cornell Quarterly 49 (4), 381-394.

Bonilla-Priego, M.J. and Avilés-Palacios, C. (2007) Percepciones de los hoteles españoles acerca de las posibilidades de las declaraciones medioambientales emitidas bajo la certificación Emas. Madrid: Rey Juan Carlos University.

Branco, M. C. and Rodrigues, L. L. (2006) Corporate social responsibility and resource-based perspectives. Journal of Business Ethics 69 (2), 111-132.

Brown, M. (1994) Environmental auditing and the hotel industry: an accountant's perspective. In A. Seaton (Ed.), Tourism: The State of the Art (pp. 675-681). Chinchester: John Wiley \& Sons.

Brown, M. (1996) Environmental policy in the hotel sector: "green" strategy or stratagem? International Journal of Contemporary Hospitality Management 8 (3), 18-23. 
Carmona-Moreno, E., Céspedes-Lorente, J. and De Burgos-Jimenez, J. (2004) Environmental Strategies in Spanish Hotels: Contextual Factors and Performance. Service Industries Journal. 24 (3), 101-130.

Cash, D. W., Clark, W. C., Alcock, F., Dickson, N. M., Eckley, N., Guston, D. H., Jäger, J. and Mitchell, R. B. (2003) Knowledge systems for sustainable development. Proceedings of the National Academy of Sciences 100 (14), 8086.

Cea D’Ancona, M. A. (2002) Análisis multivariable. Teoría y práctica en la investigación social. Madrid: Síntesis.

Céspedes, J. and De Burgos, J. (2004) Un análisis de las dimensiones de la gestión ambiental en los servicios hoteleros. Dirección y Organización 305-15.

Chan, E. and Wong, S. (2006) Motivations for ISO14001 in the hotel industry. Tourism Management 27481-492.

Chung, L. H. and Parker, L. D. (2008) Integrating Hotel Environmental Strategies with Management control: a Structuration Approach. Business Strategy and the Environment 17272-286.

Clark, D. (1999) What drives companies to seek ISO 14000 certification? Pollution Engineering International Summer (14-15).

Clausen, J., Keil, M. and Jungwirth, M. (2002) The State of EMAS in the EU. EcoManagement as a Tool for Sustainable Development, European Conference: The EU Eco-Management and Audit Scheme - Benefits and Challenges of EMAS II.

Claver-Cortés, E., Molina-Azorín, J. F., Pereira-Moliner, J. and López-Gamero, M. D. (2007) Environmental strategies and their impact on hotel performance. Journal of Sustainable Tourism 15 (6), 663-679.

Del Brío, J. A., Fernández, E. Y. and Junquera, B. (2001) Impulso medioambiental en las industrias españolas. El papel de las Administraciones Públicas. Economía Industrial 339153-166.

Dorfman, M. H., Muir W. R. and Miller C. G. (1992) Environmental Dividends: Cutting Chemical Wastes. New York: INFORM.

El Dief, M. and Font, X. (2010) The determinants of hotels' marketing managers green marketing behaviour. Journal of Sustainable Tourism 18 (2), 157-174.

El Dief, M. and Font, X. (forthcoming) Determinants of environmental management in the Red Sea Hotels: personal and organizational values and contextual variables. Journal of Hospitality \& Tourism Research in publication.

Font, X. (2007) Ecotourism certification: potential and challenges. In J. Higham (Ed.), Critical issues in ecotourism (pp. 386-405). Oxford: Butterworth-Heinemann.

Font, X. and Epler-Wood, M. (2007) Sustainable Tourism Certification Marketing and its Contribution to SME Market Access. In R. Black, \& A. Crabtree (Eds.), Quality Assurance and Certification in Ecotourism (pp. 147-163). Walingford: CABI.

Golub, J. (1998) New Instruments for Environmental Policy in the Eu. London: Routledge.

González-Benito, J. and González-Benito, O. (2005) An Analysis of the Relationship between Environmental Motivations and ISO14001 Certification. British Journal of Management 16 (2), 133-148.

González-Benito, J. and González-Benito, O. (2006a) A review of determinant factors of environmental proactivity. Business Strategy and the Environment 15 (2), 87-102. 
González-Benito, J. and González-Benito, O. (2006b) The role of stakeholder pressure and managerial values in the implementation of environmental logistics practices. International Journal of Production Research 4413531373.

González, M. and León, C. J. (2001) The adoption of environmental innovations in the hotel industry of Gran Canaria. Tourism Economics 7 (2), 177-190.

Govern de les Illes Balears (2006) Estadísticas visitas EMAS. Noviembre. Palma de Mallorca: Govern de les Illes Balears.

Hair, J. F., Anderson, R. E., Tatham, R. L. and Black, W. C. (1999) Análisis multivariante. Madrid: Prentice Hall Iberia.

Harris, L. C. and Crane, A. (2002) The greening of organizational culture. Journal of Organizational Change Management 15 (3), 214-234.

Henri, J. F. and Journeault, M. (2010) Eco-control: The influence of management control systems on environmental and economic performance. Accounting, Organizations and Society 35 (1), 63-80.

Henriques, I. Y. and Sadorsky, P. (1999) The Relationship between Environmental Commitment and Managerial Perceptions of Stakeholder Importance. Academy of Management Journal 42 (1), 87-99.

Hillary, R. (1999) Evaluation of study reports on the barriers, opportunities and drivers for small and medium sized enterprises in the adoption of environmental management systems. London: European Commission.

IHEI (2005) Sowing the seeds of change. London: International Hotels Environment Initiative.

Kirkpatrick, D. and Pouliot, C. (1996) Environmental management, ISO 14000 offers multiple rewards. Pollution Engineering 28 (6), 62-65.

Klassen, R. D. and Whybark, D. C. (1999) The impact of environmental technologies on manufacturing performance. Academy of Management Journal 42 (6), 599615.

Kolk, A., Levy, D. and Pinkse, J. (2008) Corporate Responses in an Emerging Climate Regime: The Institutionalization and Commensuration of Carbon Disclosure. European Accounting Review 17 (4), 719-745.

Kolk, A. and Mauser, A. (2002) The evolution of environmental management: from stage models to performance evaluation. Business Strategy and the Environment 1114-31.

Kollman, K. and Prakash, A. (2002) EMS-based Environmental Regimes as Club Goods: Examining Variations in Firm-level Adoption of ISO 14001 and EMAS in U.K., U.S. and Germany. Policy Sciences 35 (1), 43-67.

Lee, S. and Park, S. Y. (2009) Do socially responsible activities help hotels and casinos achieve their financial goals? International Journal of Hospitality Management 28 (1), 105-112.

MMA (2006) Estudio de opinión relativo al proceso de revisión del Reglamento (CE) $\mathrm{N}^{\circ}$ 761/2001 EMAS. Madrid: Ministerio de Medio Ambiente (MMA)/ Spanish Ministry of Environment.

Morrow, D. and Rondinelli, D. (2002) Adopting Corporate Environmental Management Systems: Motivations and Results of ISO 14001 and EMAS Certification. European Management Journal 20 (2), 159-171.

Nicolau, J. L. (2008) Corporate social responsibility: worth-creating activities. Annals of Tourism Research 35 (4), 990-1006. 
O'Dwyer, B. (2003) Conceptions of corporate social responsibility: the nature of managerial capture. Accounting, Auditing and Accountability Journal 16 (4), 523-557.

Porter, M. and van der Linde, C. (1995) Green and Competitive: Ending the Stalemate. Harvard Business Review 73 (5), 120-134.

Roome, N. (1992) Linking quality and the environment. Business Strategy and the Environment 111-24.

Rowland-Jones, R., Pryde, M. and Cresser, M. (2005) An evaluation of current environmental management systems as indicators of environmental performance. Management of Environmental Quality 16 (3), 211-219.

Sampaio, A. (2009) Environmental engagement and small tourism businesses, International Centre for Responsible Tourism (pp. 267). Leeds: Leeds Metropolitan University.

Schaefer, A. and Harvey, B. (1998) Stage Models of Corporate 'Greening': A Critical Evaluation. Business Strategy and the Environment 7 (3), 109-123.

Schaltegger, S. and Burrit, R. (2000) Contemporary environmental accounting: issues, concepts and practice. Sheffield: Greenleaf.

Schwartz, K., Tapper, R. and Font, X. (2008) A framework for sustainable supply chain management in tour operations. Journal of Sustainable Tourism 16 (3), 298-314.

Sheldon, C. and Yoxon, M. (2001) Installing environmental management systems: a step by step guide. London: Earthscan.

Siebenhüner, B. and Arnold, M. (2007) Organizational learning to manage sustainable development. Business strategy and the environment 16 (5), 339-353.

Steger, U. (2000) Environmental management systems: empirical evidence and further perspectives. European Management Journal 18 (1), 23-37.

Thomas Cook Group (2010) Carbon Disclosure Project CPD2010 Information request. Manchester: Thomas Cook plc.

Tsai, W. H., Hsu, J. L., Chen, C. H., Lin, W. R. and Chen, S. P. (2010) An integrated approach for selecting corporate social responsibility programs and costs evaluation in the international tourist hotel. International Journal of Hospitality Management in press.

Tzschentke, N., Kirk, D. and Lynch, P. A. (2004) Reasons for going green in serviced accommodation establishments. International Journal of Contemporary Hospitality Management 16 (2), 116-124.

Tzschentke, N., Kirk, D. and Lynch, P. A. (2008) Going green: Decisional factors in small hospitality operations. International Journal of Hospitality Management 27 (1), 126-133.

Vastag, G., Kerekes, S. and Rondinelli, D. A. (1996) Evaluation of corporate environmental management approaches: A framework and application. International Journal of Production Economics 43193-211.

VROM (1997) Environmental Management Systems Evaluation 1996. Den Haag: Ministrie van Volkshuisvesting, Ruimtelijke Ordening en Milieubeheer.

Ward, J. H. (1963) Hierarchical Grouping to optimize an objective function. Journal of American Statistical Association 58 (301), 236-244.

Webster, K. (2000) Environmental management in the hospitality industry: a guide for students and managers. London: Cassell.

Worthington, I. and Patton, D. (2005) Strategic intent in the management of the green environment within SMEs:: An analysis of the UK screen-printing sector. Long Range Planning 38 (2), 197-212. 
